\title{
Avaliação de risco de um sistema de transmissão elétrica
}

\section{Carlos Kreutz}

Instituto de Graduação e Pós-Graduação. Av. Carmindo de Campos, 146, Sala 55. Jardim Petrópolis. Cuiabá-MT, Brasil (CEP 78070-100). E-mail: carlos.kreutz@hotmail.com.

Resumo. Os impactos ambientais são intrínsecos a qualquer atividade de origem antrópica e passíveis de redução, de modo que a busca pelo equilíbrio entre empreendimento e meio ambiente faz com que os estudos de impacto ambiental sejam essenciais. Assim, o objetivo deste estudo foi aplicar uma das ferramentas amplamente aceitas para a avaliação de risco de um empreendimento de transmissão elétrica a ser instalado no Estado do Mato Grosso, Brasil. Tomou-se como objeto o Estudo de Impacto Ambiental da Linha de Transmissão de $500 \mathrm{kV}$ SE Jauru SE Cuiabá Circuito 2. Uma avaliação de risco é constituída de identificação do perigo, avaliação da exposição, avaliação do risco e gerenciamento do risco. Para a identificação dos perigos utilizou-se a técnica de Análise Preliminar de Perigos. Foram levantados 43 impactos ambientais sobre os meios biótico, físico e socioeconômico. Destes, 21 são classificados nos níveis de Risco I e II, sendo o meio biótico o mais atingido. No Gerenciamento de Risco, com medidas propostas para prevenir, mitigar ou compensar os riscos mais elevados, espera-se que estes sejam reduzidos ao Nível III. Acredita-se que com a aplicação das medidas propostas, eventos sinérgicos possam favorecer o bemestar do ecossistema durante e após a instalação do empreendimento.

Palavras-chave: Análise preliminar de perigos; Gestão ambiental; Impacto; Linha de transmissão.

Abstract. Risk assessment of an electrical transmission system. Environmental impacts are intrinsic to any activity of anthropic origin and subject to reduction, so that the search for a balance between enterprise and the environment makes environmental impact studies essential. Thus, the objective of this study was to apply one of the widely accepted tools for the risk assessment of an electric transmission project to be installed in the State of Mato Grosso, Brazil. The Environmental Impact Study of the 500 kV SE Jauru - SE Cuiabá Circuit 2 Transmission Line was taken as an object. A risk assessment consists of hazard identification, exposure assessment, risk assessment and risk management. For the identification of the hazards the technique of Preliminary Hazard Analysis was used. A total of 43 environmental impacts were collected on biotic, physical and socioeconomic
Recebido:

$08 / 01 / 2019$

Aceito:

$28 / 12 / 2019$

Publicado:

31/12/2019

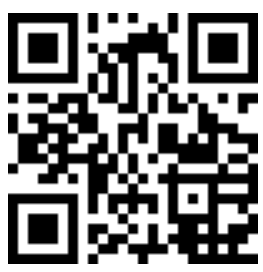

Acesso aberto

ORCID

D) 0000-0002-3668-0621

Carlos Kreutz 
environments. Of these, 21 are classified in levels of Risk I and II, and the biotic environment is the most affected. In Risk Management, with measures proposed to prevent, mitigate or compensate for the higher risks, they are expected to be reduced to Level III. It is believed that with the application of the proposed measures, synergistic events may favor the well-being of the ecosystem during and after the installation of the enterprise.

Keywords: Preliminary hazard analysis; Environmental management; Impact; Transmission line.

\section{Introdução}

Empreendimentos energéticos de grande porte como as linhas de transmissão são geralmente utilizadas para transportar a energia produzida por usinas hidrelétricas, e demais fontes geradoras, até os centros de distribuição. No Brasil, porém, a importância das linhas de transmissão vai além do simples escoamento da energia produzida, exercendo a importante função de interligar as diversas regiões do país, possibilitando que a energia produzida naquelas com maior volume de chuvas seja utilizada nas mais secas (Campos, 2010).

Linhas de transmissão de energia, bem como usinas hidrelétricas (Siqueira e Henkes, 2014), usinas fotovoltaicas (Barbosa Filho et al., 2015), sistemas produtivos industriais (Comunello et al., 2017) e qualquer outro empreendimento que demande etapas construtivas, provocam impactos no meio ambiente, seja no meio físico, biótico ou socioeconômico.

De acordo com o art. 1으, da Resolução CONAMA no 001/1986, impacto ambiental é "qualquer alteração das propriedades físicas, químicas, biológicas do meio ambiente, causada por qualquer forma de matéria ou energia resultante das atividades humanas que afetem diretamente ou indiretamente: A saúde, a segurança, o bem-estar da população; as atividades sociais e econômicas; a biota; as condições estéticas e sanitárias ambientais; e a qualidade dos recursos ambientais" (Brasil, 1986).
Assim, em relação às linhas de transmissão, as atividades associadas à sua construção, apresentam potencial de degradação significativo, principalmente no que concerne às atividades de supressão da vegetação, utilização de acessos e etapas de concretagem (Lepsch, 2010), levando à perda de biodiversidade, possível empobrecimento do solo devido a retirada de sua cobertura vegetal natural, interferência no equilíbrio dos ecossistemas, propagação da ocupação do homem em ambientes florestais (Eletrobrás, 1990), além de impactar na estrutura social e econômica dos municípios.

Portanto, sendo os impactos ambientais intrínsecos a qualquer atividade de origem antrópica e passíveis de redução, a busca pelo equilíbrio entre empreendimento e meio ambiente faz com que os estudos de impacto ambiental sejam essenciais para conhecimento da dinâmica do ecossistema pré-obra, para que sejam adotadas medidas durante a instalação e operação, reduzindo assim os riscos ao meio ambiente oriundos de determinado empreendimento (WBM, 2016).

E para avaliar o conjunto de impactos ambientais passíveis de ocorrência a partir da implantação e operação de um empreendimento podem ser utilizadas ferramentas qualitativas, semi-quantitativas ou quantitativas para identificação e avaliação de impactos ambientais, bem como análise de risco do referido empreendimento, como brainstormig, análise bow tie, HAZOP, SWIFT, APP, dentre outras (ver Pereira et 
al., 2014; Sella, 2014; Mazo e Pampolini, 2015; Comunello et al., 2017).

Com isso, o objetivo deste estudo foi aplicar uma ferramenta para a avaliação de risco de um empreendimento de transmissão elétrica a ser instalado no Estado de Mato Grosso, elaborando o Gerenciamento de Riscos Ambientais para os impactos mais graves.

\section{Material e métodos}

\section{Objeto do estudo}

Para o desenvolvimento das análises deste estudo, tomou-se como objeto o Estudo de Impacto Ambiental (EIA) da LT 500 kV SE Jauru - SE Cuiabá Circuito 2, desenvolvido por equipe multidisciplinar. 0 referido empreendimento será instalado no Estado de Mato Grosso e será paralelo ao Circuito 1 já instalado e em operação há alguns anos.

\section{Avaliação de risco}

Uma avaliação de risco é constituída, em geral, de quatro etapas básicas: I) identificação do perigo; II) avaliação da exposição; III) avaliação do risco; e IV) gerenciamento do risco (NRC, 1983). Para a identificação dos perigos utilizouse a técnica de Análise Preliminar de Perigos (APP).

A Análise Preliminar de Perigo é uma metodologia estruturada para identificar os perigos que podem ser causados devido à ocorrência de eventos indesejáveis. Esta metodologia pode ser usada para sistemas em início de desenvolvimento ou em fase de projeto, e também como revisão geral de segurança de sistemas já em operação (Moraes, 2010).

Na APP são levantadas as causas de cada um dos eventos e as suas respectivas consequências, sendo então feita uma avaliação qualitativa da frequência de ocorrência do cenário de acidente, da severidade das consequências e do risco associado.

No entanto, para o Gerenciamento dos Riscos Ambientais (GRA) é importante a proposição de medidas preventivas e/ou mitigadoras, em uma tentativa de eliminar as causas ou reduzir as consequências dos cenários identificados.

\section{Análise dos dados}

Um aspecto importante que foi considerado durante a aplicação da APP foram as diferentes fases que um mesmo impacto pode ocorrer, podendo apresentar assim diferentes magnitudes de consequência.

Todos os impactos (positivos e negativos) levantados para as diferentes fases de um empreendimento de transmissão elétrica (planejamento, instalação e operação) tiveram, inicialmente, suas causas (ações e atividades) registradas.

Os impactos, ou riscos ambientais, são compostos pela frequência de ocorrência e pela gravidade de suas consequências. Assim, para avaliar um risco é necessário estimar a frequência de ocorrência e a extensão dos danos que o mesmo pode causar, classificando-os em níveis de risco. Dessa maneira, num GRA, aqueles níveis resultantes do cruzamento de maior frequência de ocorrência com danos mais graves devem ser atacados primeiramente, buscando reduzir o nível de risco.

Para a avaliação da frequência de cada impacto, foram consideradas quatro categorias, conforme proposto por Araujo et al. (2001) e Sella (2014), com adaptações. A frequência dos impactos foi considerada em relação ao ciclo de vida do Sistema de Transmissão Elétrica, desde impactos que não são esperados que ocorram até aqueles de ocorrência bastante frequente. Considerou-se as seguintes categorias:

- 1 -Remota: Não é esperado acontecer durante o ciclo de vida útil do sistema de transmissão.

- 2 - Provável: Esperado acontecer pelo menos uma vez durante o ciclo de vida útil do sistema de transmissão. 
- 3 - Frequente: Esperado acontecer algumas vezes durante o ciclo de vida útil do sistema de transmissão.

- 4 -Muito frequente: Esperado acontecer inúmeras vezes durante o ciclo de vida útil do sistema de transmissão.

Para a avaliação da magnitude das consequências dos impactos levantados, também foram consideradas quatro categorias, conforme proposto por Araujo et al. (2001) e Sella (2014), com adaptações. A magnitude dos impactos foi considerada avaliando-se os impactos sobre os três meios: biótico, físico e socioeconômico, desde riscos que não promovam nenhum impacto negativo sobre o meio ambiente até riscos que provoquem severos danos ambientais. As categorias utilizadas foram:

- 1 - Desprezível: Nenhum dano ambiental;

- 2 - Marginal: Efeitos mínimos sobre o meio;

- 3 - Média: Efeitos moderados sobre o meio;

- 4 - Crítica: Severos danos ao meio.

Para Brown (1998), o nível de risco é função da probabilidade de ocorrência de um evento e dos seus respectivos danos. Assim, após a avaliação da frequência e da magnitude de suas consequências, foi realizada a combinação de ambas para obtenção do Nível de Risco de cada impacto levantado (Tabela 1).

Tabela 1. Categorias de Níveis de Risco para os impactos a partir da combinação das frequências e consequências dos impactos levantados.

\begin{tabular}{|c|c|c|c|c|c|}
\hline \multirow{5}{*}{ 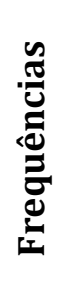 } & 4 & IV & II & I & I \\
\hline & 3 & IV & III & II & I \\
\hline & 2 & IV & IV & III & II \\
\hline & 1 & IV & IV & IV & III \\
\hline & & 1 & 2 & 3 & 4 \\
\hline
\end{tabular}

A partir do Nível de Risco, podese elaborar um plano de GRA para minimização, mitigação, compensação ou eliminação dos impactos negativos levantados, conforme a necessidade. Para os níveis de risco foram adotadas as categorias e descrições a seguir:

\section{Nível I: Não aceitável ou}

- Danos irreparáveis ao meio ambiente. 0 restabelecimento das condições primitivas do meio ambiente é lento ou impossível;

- Provoca grave impacto aos meios físico, biótico ou antrópico;
- O risco do impacto ambiental deve ser reduzido para uma categoria de risco III, através da adoção das medidas mitigadoras recomendadas e a implementação do Programa Ambiental específico, constante do Plano Básico Ambiental - PBA do empreendimento.

\section{crítico}

Nível II: Não desejável ou

- Danos severos ao meio ambiente, levando a um colapso do meio em estudo (físico, biótico ou socioeconômico) sob controle. Exige ações corretivas imediatas para evitar seu desdobramento em catástrofe. 
- Provoca impactos moderados aos meios físico, biótico ou socioeconômico. A probabilidade de acidentes ambientais irreparáveis é remota.

- O risco do impacto ambiental deve ser reduzido para uma categoria de risco III, através da adoção das medidas mitigadoras recomendadas e a implementação do Programa Ambiental específico, constante do Plano Básico Ambiental - PBA do empreendimento.

\section{ou marginal \\ Nível III: Aceitável sob controle}

- Danos leves ao meio ambiente. Os impactos são controláveis a um baixo custo e os danos ambientais são facilmente revertidos;

- Provoca impacto leve aos meios físico, biótico ou socioeconômico;

- Deve ser verificado se o sistema de prevenção/controle e os procedimentos recomendados estão confiáveis.

\section{Nível IV: Aceitável como é ou desprezível}

- Sem danos ou com danos insignificantes ao meio ambiente;

- Não ocorre impacto ao meio ambiente. 0 máximo que pode ocorrer são ameaças de impactos que podem ser facilmente eliminadas com a aplicação das medidas mitigadoras recomendadas;

- Não é necessário reduzir o risco de impacto ambiental.

Após a avaliação dos níveis de risco de cada um dos impactos ambientais levantados, foram elaboradas medidas preventivas, mitigadoras e/ou compensatórias para os impactos de natureza negativa, permitindo assim o desenvolvimento do GRA, reduzindo-se assim o impacto global do empreendimento sobre os meios físico, biótico e socioeconômico.

\section{Resultados e discussão}

\section{ambientais \\ Identificação dos impactos}

Foram relacionadas 14 atividades (em maior ou menor escala) que provocarão 23 ações com potencial impactante durante as fases de planejamento, instalação e operação da linha de transmissão objeto desse estudo. Para as ações com algum potencial causador de impacto, seja positivo ou negativo, foram levantados 43 impactos ambientais, certos ou incertos, sobre os meios biótico, físico e socioeconômico (Tabela 2).

Dentre os 43 impactos levantados, sete tem ocorrência prevista para a fase de planejamento, 34 para a fase de instalação e seis para a fase de operação. Desse total, quatro impactos podem ocorrer nas fases de instalação e operação (Tabela 2).

0 meio socioeconômico tende a ser o mais impactado (26 diferentes impactos), seguido pelo meio biótico (13) e pelo meio físico, com quatro diferentes impactos ambientais levantados. O Meio Socioeconômico tende a ser o mais impactado pelo empreendimento, pois são inúmeros e variados os impactos ambientais relacionados com esse meio, desde a perda de produção agrícola, impactos sobre a infraestrutura socioeconômica dos municípios até $\mathrm{o}$ impacto visual gerado pela inserção de um novo elemento na paisagem. Por outro lado, é nesse componente ambiental que está presente a maioria dos impactos positivos, como a geração de empregos, incremento na economia regional, propagação do conhecimento ambiental entre alunos e colaboradores.

No Meio Biótico, a supressão da vegetação será o aspecto ambiental mais 
relevante, conforme comentado por Oliveira e Zaú (1998), sendo responsável por praticamente todos os impactos sobre esse meio. Isso é devido ao fato de que os impactos sobre a fauna e flora são praticamente todos restritos à área diretamente afetada do empreendimento, ou seja, a faixa de supressão e áreas adjacentes.

A supressão vegetal além de implicar impactos sobre a fauna e flora, também gerará impactos no Meio Físico, a partir da remoção da vegetação sobre o solo e utilização de vias de acesso, e no Socioeconômico, geração de ruídos e riscos de acidente de trabalho. Do mesmo modo, o fluxo de veículos pelas vias de acesso gera impactos sinérgicos nos três meios analisados, sendo responsável pela geração ou ampliação de processos erosivos que podem carrear sedimentos e alterar as características físicoquímicas de corpos hídricos próximos, provocar o atropelamento de espécimes da fauna local, gerar ruídos, provocar a deterioração das estradas locais e aumentar os riscos de acidentes de trânsito.

Apesar da ocorrência certa e natureza negativa da maioria dos impactos identificados, a maioria possui algum grau de reversibilidade, podendo o aspecto ambiental retornar ao seu estado anterior ao empreendimento ou próximo disso. Além disso, grande parte dos impactos irreversíveis ou parcialmente reversíveis possui natureza positiva, ou seja, serão consequências positivas oriundas do empreendimento que permanecerão na região mesmo após o término das atividades.

\section{Análise de risco}

A análise dos Níveis de Risco revelou que dos 43 impactos (positivos e negativos), 11 estão classificados como Nível I, que agrupa os riscos não aceitáveis ou catastróficos (Tabela 3). É a categoria dos riscos que podem provocar danos irreparáveis ao meio ambiente, em um ou mais dos meios avaliados, tais como o atropelamento de fauna, a perda de hábitats e a deterioração de estradas e vias locais. São riscos que necessitam da aplicação e monitoramento de rigorosas medidas preventivas ou mitigadoras, que promovam a elevação destes riscos ao Nível III, posteriormente.

O Nível II apresentou 10 impactos, que são categorizados como riscos não desejáveis ou críticos (Tabela 3), entre eles estão o carreamento de sedimentos e interferências no fluxo dos cursos d'água, acidentes com animais peçonhentos e demandas adicionais sobre a infraestrutura dos municípios. São riscos que provocam danos graves ao meio ambiente como um todo, necessitando também de medidas preventivas e mitigadoras para evitar que evoluam para danos irreparáveis ao meio em estudo, e fazendo com que o nível destes seja também elevado para Nível III. 
Tabela 2. Lista dos impactos ambientais identificados com os respectivos atributos, atividades e ações causadoras, para todos os meios analisados, nas fases de planejamento, implantação e operação da LT 500 kV SE Jauru - SE Cuiabá C2. $P$ = Positivo; $N$ = Negativo; $C$ = Certo; $I=$ Incerto.

\begin{tabular}{|c|c|c|c|c|c|}
\hline$\frac{9}{2}$ & Atividade & Ação & Impacto Ambiental & 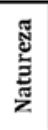 & 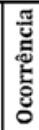 \\
\hline \multicolumn{6}{|c|}{ FASE DE PLANEJAMENTO } \\
\hline$\frac{8}{\frac{d}{6}}$ & Definição da faixa de servidão & $\begin{array}{l}\text { Interferência em áreas com processos } \\
\text { minerários }\end{array}$ & Perda dos direitos minerários & $\mathrm{N}$ & C \\
\hline \multirow{6}{*}{ 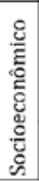 } & \multirow{4}{*}{$\begin{array}{l}\text { Definição do traçadio e levantamento } \\
\text { das propriedades atingidas }\end{array}$} & \multirow{3}{*}{ Restrição ao uso do solo } & Bloqueio de títulos minerários & $\mathrm{N}$ & C \\
\hline & & & Perda de área de benfeitorias & $\mathrm{N}$ & C \\
\hline & & & Perda de produção agrícola & $\mathrm{N}$ & C \\
\hline & & Inserção de novo elemento na paisagem & Alterações na paisagem local & $\mathrm{N}$ & C \\
\hline & \multirow{2}{*}{ Estudos preliminares } & \multirow{2}{*}{ Divulgação do empreendimento } & Expectativas desfavoráveis na população & $\mathrm{N}$ & C \\
\hline & & & Expectativas favoráveis na população & $\mathrm{P}$ & C \\
\hline \multicolumn{6}{|c|}{ FASE DE INSTALAÇÃO } \\
\hline \multirow{4}{*}{$\frac{8}{\frac{.}{6}}$} & Abertura e uso de vias de acesso & \multirow{2}{*}{ Remoção da vegetação } & \begin{tabular}{|c|}
$\begin{array}{c}\text { Carreamento de sedimentos e interferência no fluxo } \\
\text { dos cursos d'água }\end{array}$ \\
\end{tabular} & $\mathrm{N}$ & I \\
\hline & Abertura das praças de torre & & \multirow[t]{2}{*}{ Início e/ou aceleração de processos erosivos } & \multirow[t]{2}{*}{$\mathrm{N}$} & \multirow[t]{2}{*}{ I } \\
\hline & Instalação dos canteiros de obras & Uso e ocupação do solo & & & \\
\hline & Obras civis & $\begin{array}{l}\text { Despejo de resíduos sobre o solo e/ou } \\
\text { próximo a corpos hídricos }\end{array}$ & $\begin{array}{c}\begin{array}{c}\text { Alteração nas características físico-químicas do solo } \\
\text { e da água superficial e subterrânea }\end{array} \\
\end{array}$ & $\mathrm{N}$ & I \\
\hline \multirow{7}{*}{ 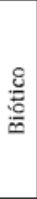 } & \multirow{7}{*}{$\begin{array}{l}\text { Abertura de áreas de vão, torre e } \\
\text { acessos }\end{array}$} & \multirow{7}{*}{ Remoção da vegetação } & \begin{tabular}{|l|} 
Perda de espécimes arbóreos \\
\end{tabular} & $\mathrm{N}$ & C \\
\hline & & & Perda de epífitas e hemiepífitas & $\mathrm{N}$ & C \\
\hline & & & Perda de material de propagação & $\mathrm{N}$ & C \\
\hline & & & Quedas adicionais de espécimes (vento) & $\mathrm{N}$ & C \\
\hline & & & Fragmentaçâo e efeito de borda & $\mathrm{N}$ & C \\
\hline & & & Interrupção do fluxo gênico & $\mathrm{N}$ & C \\
\hline & & & Mortandade da fauna & $\mathrm{N}$ & C \\
\hline
\end{tabular}

Tabela 2. Continuação.

\begin{tabular}{|c|c|c|c|c|c|}
\hline 边 & Atividade & Ação & Impacto Ambiental & 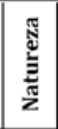 & 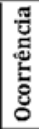 \\
\hline & & & Acidentes com animais peçonhentos & $\mathrm{N}$ & C. \\
\hline & & & Aumento da caça & $\mathrm{N}$ & $\mathrm{C}$ \\
\hline & & & Migração compulsória & $\mathrm{N}$ & $\mathrm{C}$ \\
\hline & & & Perda de hábitat & $\mathrm{N}$ & C \\
\hline & Construção da LT & Fluxo de veículos & Atropelamento da fauna & $\mathrm{N}$ & $\mathrm{C}$ \\
\hline \multirow{16}{*}{ 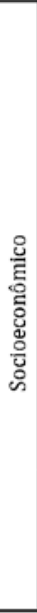 } & \multirow{12}{*}{ Construção da LT } & Geração de resíduos & $\begin{array}{c}\text { Alteração das características físico-químicas do solo } \\
\text { e da água }\end{array}$ & $\mathrm{N}$ & I \\
\hline & & Destinaçâo dos resíduos gerados & $\begin{array}{c}\begin{array}{l}\text { Sobrecarga no sistema municipal de coleta e } \\
\text { destinação }\end{array} \\
\end{array}$ & $\mathrm{N}$ & C \\
\hline & & \multirow{2}{*}{ Terraplenagem e remoção de solo } & Danificar ou soterrar vestígios arqueológicos & $\mathrm{N}$ & I \\
\hline & & & Identificar novos sítios arqueológicos & $\mathrm{P}$ & $\mathrm{I}$ \\
\hline & & Montagem das torres & \multirow{3}{*}{ Risco de acidentes de trabalho } & \multirow{3}{*}{$\mathrm{N}$} & \multirow{3}{*}{ I } \\
\hline & & Lançamento dos cabos & & & \\
\hline & & Ampliação das subestações & & & \\
\hline & & \multirow{5}{*}{ Contratação de mão de obra e serviços } & Geração de empregos diretos e indiretos & $\mathrm{P}$ & C \\
\hline & & & Migração de mão de obra & $\mathrm{P}$ & $\mathrm{C}$ \\
\hline & & & \begin{tabular}{|c|} 
Risco de conflito entre a mão de obra contratada e a \\
população local
\end{tabular} & $\mathrm{N}$ & I \\
\hline & & & \begin{tabular}{|c}
$\begin{array}{c}\text { Demandas adicionais sobre a infraestrutura social } \\
\text { local }\end{array}$ \\
\end{tabular} & $\mathrm{N}$ & C \\
\hline & & & Afluxo populacional para a região & $\mathrm{P} / \mathrm{N}$ & $\mathrm{C}$ \\
\hline & \multirow{4}{*}{ Construçåo da LT } & \multirow[t]{2}{*}{ Arrecadação de impostos } & $\begin{array}{c}\text { Elevação das receitas tributáveis municipais e } \\
\text { estaduais }\end{array}$ & $\mathrm{P}$ & C \\
\hline & & & Incremento da economia regional & $\mathrm{P}$ & C \\
\hline & & Remoção da vegetação & \multirow{2}{*}{ Geração de ruídos } & \multirow{2}{*}{$\mathrm{N}$} & \multirow{2}{*}{ C } \\
\hline & & Fluxo de veículos & & & \\
\hline
\end{tabular}


Tabela 2. Continuação.

\begin{tabular}{|c|c|c|c|c|c|}
\hline$\frac{9}{2}$ & Atividade & Ação & Impacto Ambiental & 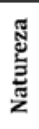 & 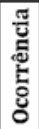 \\
\hline & & $\begin{array}{l}\text { Montagem de torres e lançamento de } \\
\text { cabos }\end{array}$ & & & \\
\hline & & Operação de áreas de apoio & & & \\
\hline & \multirow[t]{2}{*}{ Palestras de educação ambiental } & \multirow{2}{*}{$\begin{array}{l}\text { Interação com as escolas públicase } \\
\text { colaboradores }\end{array}$} & $\begin{array}{l}\text { Propagação de conhecimento sobre o meio } \\
\text { ambiente }\end{array}$ & $\mathrm{P}$ & C: \\
\hline & & & Sensibilização sobre destinação de resíduos & $\mathrm{P}$ & C. \\
\hline & \multirow{2}{*}{$\begin{array}{l}\text { Construção das torres e lançamento } \\
\text { dos cabos }\end{array}$} & \multirow{2}{*}{ Utilização de vias locais } & Deterioração das estradas e vias locais & $\mathrm{N}$ & $\mathrm{C}$ \\
\hline & & & Riscos de acidentes de trânsito & $\mathrm{N}$ & $\mathrm{I}$ \\
\hline & Lançamento de cabos & Instalação de travessia & Desvios e/ou interrupções de tráfego & $\mathrm{N}$ & $\mathrm{C}$ \\
\hline & Finalização da obra & Rescisão contratual com colaboradores & Redução da razão oferta/demanda de emprego & $\mathrm{N}$ & C \\
\hline \multicolumn{6}{|c|}{ FASE DE OPERAÇÃO } \\
\hline \multirow{2}{*}{$\frac{8}{\frac{0}{5}}$} & \multirow{2}{*}{ Manutenção da LT } & \multirow{2}{*}{ Uso dos acessos } & $\begin{array}{l}\text { Carreamento de sedimentos e interferência do fluxo } \\
\text { dos cursos d'água }\end{array}$ & $\mathrm{N}$ & I \\
\hline & & & Início e/ou aceleração de processos erosivos & $\mathrm{N}$ & I \\
\hline$\frac{8}{0}$ & Manutenção da LT & Poda e desbaste da faixa de serviço & Inibição da regeneração natural & $\mathrm{N}$ & C \\
\hline \multirow{4}{*}{ 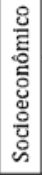 } & Construção da LT & Energização da LT & Expansão do sistema de transmissão nacional & $P$ & C \\
\hline & \multirow{3}{*}{ Manutenção da LT } & Fluxo de veículos & \multirow{2}{*}{ Geração de ruídos } & \multirow{2}{*}{$\mathrm{N}$} & \multirow{2}{*}{ C } \\
\hline & & Poda e desbaste da faixa de serviço & & & \\
\hline & & Contratação de mão de obra & Geração de empregos diretos & $\mathrm{P}$ & C \\
\hline
\end{tabular}

A categoria que apresenta os riscos aceitáveis sob controle ou marginais, Nível III, apresentou cinco impactos (Tabela 3). São impactos que podem levar a danos leves ao meio ambiente, como a geração de ruídos, riscos de acidente de trânsito e danos à vestígios arqueológicos, com possuem controle fácil e impactos podem ser facilmente revertidos, desde que um plano de medidas preventivas eficiente seja posto em prática.

Por fim, o Nível IV, que agrupa os riscos aceitáveis como são ou desprezíveis, apresentou 17 impactos (Tabela 3). É a categoria mais desejável em uma
Avaliação Preliminar de Perigos, uma vez que são riscos que não provocam danos ao meio ambiente ou então seus impactos são insignificantes, tais como a perda de direitos minerários, desvios e/ou interrupções de tráfego e perda de produção agrícola. Neste estudo, a maioria dos impactos dessa categoria são do Meio Socioeconômico, além de agrupar todos os impactos positivos levantados na identificação de impactos ambientais realizada, pois estes não apresentam dados ao meio ambiente e por isso são categorizados no menor nível de consequência.

Tabela 3. Frequências, consequências e níveis de risco dos impactos levantados durante avaliação de impactos ambientais para três fases do empreendimento LT 500 kV SE Jauru - SE Cuiabá C2. Freq. $=$ Frequência; Conseq. $=$ Consequência.

\begin{tabular}{|c|c|c|c|c|}
\hline Meio & Impacto & Freq. & Conseq. & $\begin{array}{l}\text { Nível de } \\
\text { Risco }\end{array}$ \\
\hline \multirow{3}{*}{ 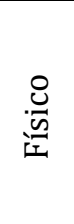 } & $\begin{array}{l}\text { Alteração nas características físico-químicas do solo e da água } \\
\text { superficial e subterrânea }\end{array}$ & 2 & 4 & Nível II \\
\hline & $\begin{array}{l}\text { Carreamento de sedimentos e interferência no fluxo dos } \\
\text { cursos d'água }\end{array}$ & 3 & 3 & Nível II \\
\hline & Início e/ou aceleração de processos erosivos & 3 & 3 & Nível II \\
\hline
\end{tabular}


Tabela 3. Continuação.

\begin{tabular}{|c|c|c|c|c|}
\hline Meio & Impacto & Freq. & Conseq. & $\begin{array}{c}\text { Nível de } \\
\text { Risco } \\
\end{array}$ \\
\hline & Perda dos direitos minerários & 2 & 2 & Nível IV \\
\hline \multirow{13}{*}{$\begin{array}{l}\stackrel{0}{ت} \\
: 00 \\
: 0\end{array}$} & Acidentes com animais peçonhentos & 3 & 3 & Nível II \\
\hline & Atropelamento da fauna & 4 & 3 & Nível I \\
\hline & Aumento da caça & 2 & 3 & Nível III \\
\hline & Fragmentação e efeito de borda & 4 & 2 & Nível II \\
\hline & Inibição da regeneração natural & 4 & 2 & Nível II \\
\hline & Interrupção do fluxo gênico & 3 & 2 & Nível III \\
\hline & Migração compulsória & 3 & 3 & Nível II \\
\hline & Mortandade da fauna & 4 & 4 & Nível I \\
\hline & Perda de epífitas e hemiepífitas & 4 & 3 & Nível I \\
\hline & Perda de espécimes arbóreos & 4 & 3 & Nível I \\
\hline & Perda de hábitat & 3 & 4 & Nível I \\
\hline & Perda de material de propagação & 4 & 3 & Nível I \\
\hline & Quedas adicionais de espécimes (vento) & 3 & 3 & Nível II \\
\hline \multirow{22}{*}{ 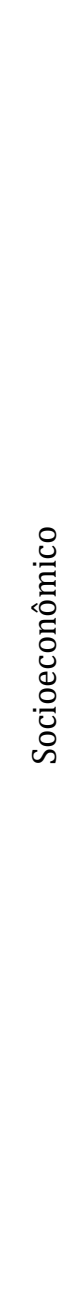 } & Afluxo populacional para a região & 4 & 3 & Nível I \\
\hline & Alteração das características físico-químicas do solo e da água & 2 & 4 & Nível II \\
\hline & Alterações na paisagem local & 4 & 3 & Nível I \\
\hline & Bloqueio de títulos minerários & 2 & 1 & Nível IV \\
\hline & Danificar ou soterrar vestígios arqueológicos & 3 & 2 & Nível III \\
\hline & Demandas adicionais sobre a infraestrutura social local & 4 & 2 & Nível II \\
\hline & Desvios e/ou interrupções de tráfego & 3 & 1 & Nível IV \\
\hline & Deterioração das estradas e vias locais & 4 & 3 & Nível I \\
\hline & Elevação das receitas tributáveis municipais e estaduais & 4 & 1 & Nível IV \\
\hline & Expansão do sistema de transmissão nacional & 4 & 1 & Nível IV \\
\hline & Expectativas desfavoráveis na população & 3 & 1 & Nível IV \\
\hline & Expectativas favoráveis na população & 3 & 1 & Nível IV \\
\hline & Geração de empregos diretos e indiretos & 4 & 1 & Nível IV \\
\hline & Geração de ruídos & 3 & 2 & Nível III \\
\hline & Identificar novos sítios arqueológicos & 2 & 1 & Nível IV \\
\hline & Incremento da economia regional & 4 & 1 & Nível IV \\
\hline & Migração de mão de obra & 4 & 3 & Nível I \\
\hline & Perda de área de benfeitorias & 4 & 1 & Nível IV \\
\hline & Perda de produção agrícola & 4 & 1 & Nível IV \\
\hline & Propagação de conhecimento sobre o meio ambiente & 4 & 1 & Nível IV \\
\hline & Redução da razão oferta/demanda de emprego & 3 & 1 & Nível IV \\
\hline & Risco de acidentes de trabalho & 3 & 1 & Nível IV \\
\hline
\end{tabular}


Tabela 3. Continuação.

\begin{tabular}{|l|l|c|c|c|}
\hline \multicolumn{1}{|c|}{ Impacto } & \multicolumn{1}{|c|}{ Imo } & Freq. & Conseq. & $\begin{array}{c}\text { Nível de } \\
\text { Risco }\end{array}$ \\
\hline \multirow{2}{*}{$\begin{array}{l}\text { Risco de conflito entre a mão de obra contratada e a } \\
\text { população local }\end{array}$} & 2 & 1 & Nível IV \\
\cline { 2 - 5 } & Riscos de acidentes de trânsito & 3 & 2 & Nível III \\
\cline { 2 - 5 } & Sensibilização sobre destinação de resíduos & 4 & 1 & Nível IV \\
\cline { 2 - 5 } & Sobrecarga no sistema municipal de coleta e destinação & 4 & 4 & Nível I \\
\hline
\end{tabular}

Dentre os 21 riscos de Nível I ou Nível II que precisam ser combatidos com medidas preventivas ou mitigadoras, três pertencem ao Meio Físico, sete ao Meio Socioeconômico e 11 ao Biótico.

O conjunto de medidas para prevenir ou mitigar os riscos que podem provocar danos graves ou irreparáveis ao meio ambiente segue descrito na Tabela 4.

Apesar de o nível de risco catastrófico ou crítico desses danos ambientais, muitos são total ou parcialmente reversíveis, devolvendo ao meio correspondente condições e características similares às encontradas anteriormente à instalação do empreendimento, quando aplicadas corretamente as medidas propostas.

Em relação aos impactos sobre o meio físico, as atividades construtivas (escavações, aberturas de áreas de torre, acessos e utilização destes) são as principais responsáveis pelos níveis de risco mais elevados, como processos erosivos, carreamento de sedimentos para cursos d'água e alteração das características do solo e da água superficial e subterrânea. No entanto, a adoção correta e periódica das medidas propostas na Tabela 3 , poderão evitar completamente ou substancialmente os impactos previstos. De acordo com Oliveira e Zaú (1998), o papel do desmatamento no início de processos erosivos diz respeito aos efeitos de desproteção da cobertura vegetal sobre o solo, levando à desestruturação dos solos a partir do impacto direto da chuva.
Sobre a fauna e flora, a principal causa dos impactos previstos é a supressão da vegetação para abertura de acessos, praças de torre e vãos. Não obstante a perda de espécimes arbóreos ser inevitável, esta pode ser minimizada com a adoção de algumas medidas, como a redução da faixa a ser suprimida. Esta prática sinergicamente reduz outros impactos, como perda de material de propagação, de epífitas e hemiepífitas, de habitats, mortandade de fauna, acidentes com animais peçonhentos, entre outros. Embora a faixa de servidão definida pela ANEEL (Agência Nacional de Energia Elétrica) em seu Relatório R3 (Eletrobrás - Eletronorte, 2014) tenha sido de $60 \mathrm{~m}$ (passível de supressão), a adoção de faixas mínimas de $10 \mathrm{~m}$ para áreas de floresta e $5 \mathrm{~m}$ para áreas de cerrado reduz significativamente os danos sobre o meio biótico.

Além disso, no cenário atual da região do empreendimento, diferentes atividades econômicas têm-se instalado nas áreas rurais tomando cada vez mais espaço, fragmentando cada vez mais os remanescentes de vegetação, restringindo os hábitats da fauna e fluxo gênico das espécies de fauna e flora, principalmente atividades agropecuárias, com foco maior na produção animal (WBM, 2016). De acordo com Araujo et al. (2010), o sistema de produção animal extensiva, bastante comum na região de instalação do empreendimento, é caracterizado pelo super pastoreio que provoca alterações significativas na superfície do solo e composição das espécies vegetais, pois intensifica tanto a 
compactação do solo quanto a subtração da cobertura vegetal nativa.

Ainda, a produção agrícola com suas monoculturas, uso de agrotóxicos de maneira inadequada e uso intensivo do solo, provocam a fragmentação de maciços florestais, desgaste do solo, alterações da química do solo e das águas subterrâneas e superficiais, levando à degradação do meio ambiente (Deus e Bakonyi, 2012).

No que se refere às alterações na paisagem, cabe ressaltar que, a despeito da introdução de um novo elemento na paisagem, a região percorrida pelo empreendimento já se encontra, em grande parte, alterada, com predomínio de culturas agrícolas e manutenção de remanescentes florestais apenas no entorno das drenagens. As alterações na paisagem serão mais significativas no entorno dos principais cursos d'água a serem interceptados pela LT, onde se encontram os fragmentos de vegetação nativa mais preservados, embora essas regiões já sejam atravessadas por outras linhas de transmissão (WBM, 2016).

Portanto, ao se manter o paralelismo com as linhas existentes e adotar decisões de localização de traçado que minimizem as travessias em área de acesso restrito que exijam a abertura de caminhos de acesso, o empreendimento reduz o impacto visual produzido. Ainda, a poda seletiva de árvores nas bordas da faixa de servidão, travessias de estradas e rodovias em diagonal e adoção de torres mais baixas quando a LT se destaca no horizonte (Furnas, 1985) são práticas para reduzir o impacto visual.

Tabela 4. Gerenciamento de Riscos Ambientais para os impactos identificados durante a Identificação de Impactos Ambientais para três fases do projeto da LT 500 kV SE Jauru - SE Cuiabá C2. $P P R A=$ Programa de Prevenção de Riscos Ambientais; PCMSO = Programa de Controle Médico de Saúde Ocupacional.

\begin{tabular}{|c|c|c|c|c|}
\hline Meio & Impacto & $\begin{array}{c}\text { Nivel } \\
\text { de } \\
\text { Risco }\end{array}$ & Medidas Preventivas e/ou Mitigadoras & Programa de Monitoramento \\
\hline \multirow{3}{*}{$\stackrel{8}{8}$} & $\begin{array}{l}\text { Carreamento de sedimentos e } \\
\text { interferência no fluxo dos cursos } \\
\text { d'água }\end{array}$ & Nivel II & \multirow{3}{*}{$\begin{array}{l}\checkmark \text { Instalação de canaletas, curva de nível evaletas laterais para } \\
\text { direcionamento do fluxo superficial da água; } \\
\checkmark \text { Instalação de manilhas em cursos d’água com } \\
\text { encabeçamento adequado; } \\
\checkmark \text { Manutenção prévia dos acessos já existentes; } \\
\checkmark \text { Planejamento adequado das vias de acessos; } \\
\checkmark \text { Reconstituição da camada de solo erodida; } \\
\checkmark \text { Revegetação das áreas de torre. } \\
\checkmark \text { Elaboração de análise de água; } \\
\checkmark \text { Lavagem de caminhões betoneira em local adequado; } \\
\checkmark \text { Manutenção de maquinário em local adequado; } \\
\checkmark \text { Medidas emergenciais para reparação de contaminação em } \\
\text { águas superficiais; } \\
\checkmark \text { Uso de kits de mitigação para o abastecimento de } \\
\text { equipamentos. }\end{array}$} & \multirow{3}{*}{$\begin{array}{l}\checkmark \text { Prog. Ambiental para } \\
\text { Construção; } \\
\checkmark \text { Prog. de Monitoramento e } \\
\text { Controle de Processos Erosivos. }\end{array}$} \\
\hline & $\begin{array}{l}\text { Início e/ou aceleração de } \\
\text { processos erosivos }\end{array}$ & Nível II & & \\
\hline & $\begin{array}{l}\text { Alteração nas características } \\
\text { físico-químicas do solo e da água } \\
\text { superficial e subterrânea }\end{array}$ & Nivel II & & \\
\hline \multirow{4}{*}{ 串 } & Atropelamento da fauna & Nível I & $\begin{array}{l}\text { Instalação de indutores de diminuição de velocidade; } \\
\checkmark \text { Palestras educativas com os colaboradores; } \\
\checkmark \text { Placas de sinalização indicativas. }\end{array}$ & $\begin{array}{l}\checkmark \text { Prog de Resgate e } \\
\text { Afugentamento de Fauna; } \\
\checkmark \text { Prog. de Educaçăo Ambiental. }\end{array}$ \\
\hline & Mortandade da fauna & Nível I & $\begin{array}{l}\checkmark \text { Afugentar a fauna silvestre por meio de métodos passivos e } \\
\text { não invasivos. }\end{array}$ & $\begin{array}{l}\checkmark \text { Prog de Resgate e } \\
\text { Afugentamento de Fauna. }\end{array}$ \\
\hline & Perda de epífitas e hemiepifitas & Nível I & $\begin{array}{l}\checkmark \text { Redução da largura da faixa a ser suprimida; } \\
\checkmark \text { Priorizar a utilização dos acessos já existentes; } \\
\checkmark \text { Resgate e realocação dos espécimes. }\end{array}$ & 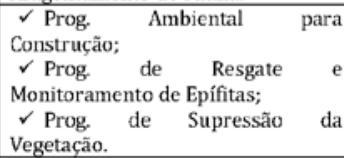 \\
\hline & Perda de material de propagação & Nível I & $\begin{array}{l}\checkmark \text { Coletar sementes de espécies registradas pelo Inventário } \\
\text { Florestal; } \\
\checkmark \text { Plantio compensatório de espécies atingidas pela supressão } \\
\text { da vegetação; } \\
\checkmark \text { Priorizar a utilização dos acessos já existentes. }\end{array}$ & $\begin{array}{l}\text { Prog. Ambiental para } \\
\text { Construçăo; } \\
\checkmark \text { Prog. de Coleta de sementes; } \\
\checkmark \text { Prog de Educação Ambiental; } \\
\checkmark \text { Prog de Recuperação de Áreas }\end{array}$ \\
\hline
\end{tabular}


Tabela 4. Continuação.

\begin{tabular}{|c|c|c|c|c|}
\hline Meio & Impacto & $\begin{array}{l}\text { Nivel } \\
\text { de } \\
\text { Risco }\end{array}$ & Medidas Preventivas e/ou Mitigadoras & Programa de Monitoramento \\
\hline & & & & Degradadas. \\
\hline & Perda de espécimes arbóreos & Nivel I & \multirow{3}{*}{$\begin{array}{l}\checkmark \text { Priorizar a utilização dos acessos já existentes; } \\
\checkmark \text { Reduçẫo da largura da faixa a ser suprimida. }\end{array}$} & \multirow{3}{*}{ 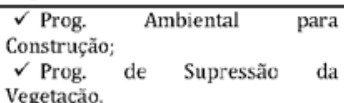 } \\
\hline & \begin{tabular}{|l|} 
Perda de hábitat \\
\end{tabular} & Nive! I & & \\
\hline & Fragmentação e efeito de borda & Nível II & & \\
\hline & \begin{tabular}{|lll}
$\begin{array}{l}\text { Acidentes } \\
\text { peçonhentos }\end{array}$ & com animais
\end{tabular} & Nível II & $\begin{array}{l}\text { Afugentamento adequado da fauna antes das atividades de } \\
\text { supressão da vegetação; } \\
\checkmark \text { Palestras educativas com os colaboradores; } \\
\checkmark \text { Uso de equipamentos de proteção individual. }\end{array}$ & $\begin{array}{l}\checkmark \text { Prog. de Resgate e } \\
\text { Afugentamento de Fauna; } \\
\checkmark \text { Prog. de Saúde e Segurança do } \\
\text { Trabalho. }\end{array}$ \\
\hline & Migração compulsória & Nível II & $\begin{array}{l}\checkmark \text { Afugentar a fauna silvestre por meio de métodos passivos e } \\
\text { não invasivos; } \\
\checkmark \text { Priorizar a utilização dos acessos já existentes; } \\
\checkmark \text { Reduçẫo da largura da faixa a ser suprimida. }\end{array}$ & $\begin{array}{l}\checkmark \text { Prog. de Conservação da Fauna } \\
\text { Ameaçada de Extinção; } \\
\checkmark \text { Prog. de Resgate e } \\
\text { Afugentamento de Fauna. }\end{array}$ \\
\hline & $\begin{array}{l}\text { Quedas adicionais de espécimes } \\
\text { (vento) }\end{array}$ & Nível II & \multirow{2}{*}{$\checkmark$ Redução da largura da faixa a ser suprimida; } & $\begin{array}{ccc}\checkmark \text { Prog. de Supressão } & \text { da } \\
\text { vegetação; } & & \\
\end{array}$ \\
\hline & Inibição da regeneração natural & Nível II & & $\begin{array}{l}\checkmark \text { Prog. de Manejo da Regeneraçăo } \\
\text { Natural. }\end{array}$ \\
\hline \multirow{3}{*}{ 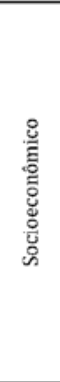 } & Afluxo populacional para a região & Nível I & \multirow{2}{*}{$\begin{array}{l}\checkmark \text { Compensaçăo socioeconômica aos municípios afetados } \\
\text { devido à sobrecarga na infraestrutura; } \\
\checkmark \text { Contratação de trabalhadores e de pequenas empresas } \\
\text { localizadas nos municípios da Área de Influência Direta e } \\
\text { Indireta; } \\
\checkmark \text { Cursos de qualificação para a mão de obra contratada; } \\
\checkmark \text { Divulgação prévia do empreendimento e do encerramento } \\
\text { das atividades, com incentivo do retorno dos colaboradores aos } \\
\text { seus locais de origem; }\end{array}$} & \multirow{2}{*}{$\begin{array}{l}\checkmark \text { Prog. de Capacitação } \\
\text { Profissional na Área de Construção } \\
\text { de Linhas de Transmissão; } \\
\checkmark \text { Prog. de Comunicação Social; }\end{array}$} \\
\hline & Migração de mão de obra & Nivel I & & \\
\hline & $\begin{array}{l}\text { Deterioração das estradas e vias } \\
\text { locais }\end{array}$ & Nivel I & $\begin{array}{l}\checkmark \text { Adoção de normas para a redução de velocidade em pontos } \\
\text { críticos que representam potencial ocorrência de acidentes; } \\
\checkmark \text { Informar e esclarecer a população residente ao longo do } \\
\text { traçado do empreendimento sobre a utilização das vias por } \\
\text { maquinário e veículos da obra; } \\
\checkmark \text { Manutenção de acessos; }\end{array}$ & $\begin{array}{l}\checkmark \text { Prog. Ambiental para a } \\
\text { Construção; } \\
\checkmark \text { Prog. de Comunicação Social; } \\
\checkmark \text { Prog. de Educação Ambiental; } \\
\checkmark \text { Prog. de Gestão Ambiental. }\end{array}$ \\
\hline
\end{tabular}

Tabela 4. Continuação.

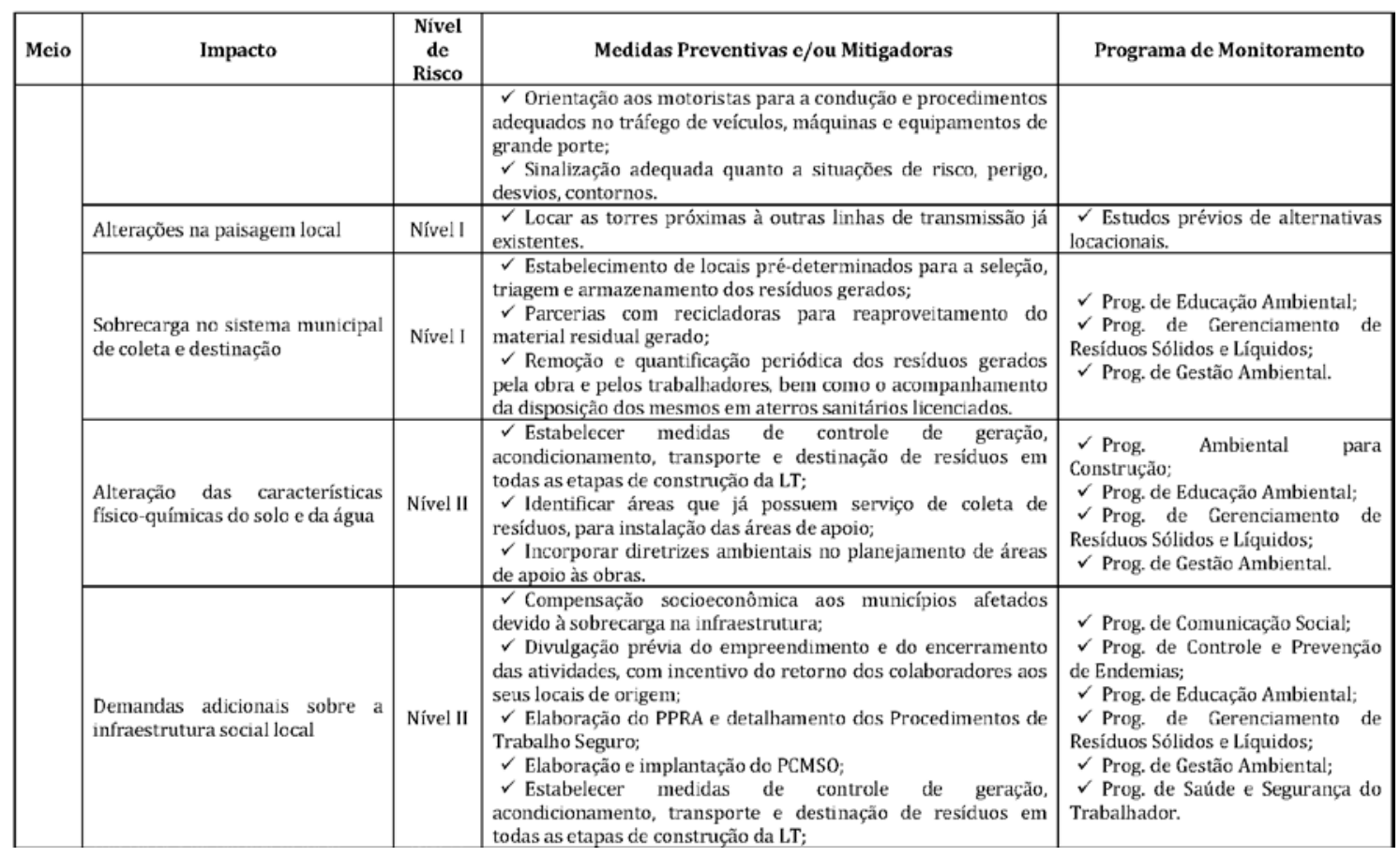


Tabela 4. Continuação.

\begin{tabular}{|c|c|c|c|c|}
\hline Meio & Impacto & $\begin{array}{c}\text { Nivel } \\
\text { de } \\
\text { Risco }\end{array}$ & Medidas Preventivas e/ou Mitigadoras & Programa de Monitoramento \\
\hline & & & $\begin{array}{l}\checkmark \text { Gestão da segurança do trabalho e da saúde ocupacional; } \\
\checkmark \text { Instalação de canteiros e alojamentos nos municípios que } \\
\text { apresentam maior infraestrutura socioeconômica; } \\
\checkmark \text { Instalação de posto médico e ambulatório capacitado para } \\
\text { atendimentos realizados por um profissional de enfermagem; } \\
\checkmark \text { Pactuação junto aos representantes das Secretarias } \\
\text { Municipais de Saúde dos munićpios atingidos; } \\
\checkmark \text { Realização de exames de saúde; } \\
\checkmark \text { Realização de palestras preventivas em parceria com a } \\
\text { segurança pública. }\end{array}$ & \\
\hline
\end{tabular}

\section{Conclusão}

É de se ponderar que, de maneira geral, o processo de fragmentação florestal encontra-se em estágio avançado em muitos trechos do corredor de estudos, devido às atividades agropecuárias que avançam em área a cada ano, a supressão da vegetação nativa para a implantação da futura linha de transmissão não causará impactos de alta magnitude e intensidade. A composição faunística ao longo do traçado proposto é bastante similar, resultado de uma igualdade na integridade e qualidade ambiental causada principalmente por essa fragmentação generalizada.

Ao se sopesar os aspectos sociais, econômicos e ambientais, o empreendimento terá inúmeros malefícios compensados pelos benefícios proporcionados. Como qualquer atividade antrópica, o referido projeto também causará impactos ambientais. Apesar de terem sido identificados diversos impactos ambientais oriundos do planejamento, instalação e operação do empreendimento, estes poderão ser devidamente mitigados, prevenidos ou compensados, caso as medidas e programas propostos pelo Gerenciamento de Riscos Ambientais sejam corretamente seguidos.

No entanto, para o meio socioeconômico será de fundamental importância a adoção dessas medidas, uma vez que os municípios apresentam atualmente muitas deficiências com relação à saúde, moradia, saneamento, educação e segurança, de modo que o aporte trabalhista que chegará em alguns lugares poderá potencializar esses problemas.

Por outro lado, é importante salientar que, igualmente à sinergia quanto à ocorrência dos impactos, também ocorrerá eventos sinérgicos quando dá aplicação de medidas preventivas, mitigadoras ou compensatórias, em que a reversão de um ou mais impactos provocará a reversão concomitante de diversos outros impactos ocorridos nos meios avaliados.

\section{Agradecimentos}

Sinceros agradecimentos à equipe multidisciplinar responsável pelo estudo de impacto ambiental e que contribuiu significativamente na avaliação de impactos ambientais, que subsidiaram este estudo: o engenheiro ambiental Wagner de F. Rodrigues Junior; os engenheiros florestais Elaine C. P. Alonso, Luana P. A. De Lamônica e Rafhael M. C. Dutra; o geólogo Wagnan H. A. de Melo; a bióloga Ana Paula R. S. Cunha; as arqueólogas Suzana Hirooka e Sirlei Hoeltz; bem como a todos que participaram das equipes específicas.

\section{Conflito de interesses}

0 autor declara não haver conflito de interesses. 


\section{Referências}

Araujo, F. J. C.; Adissi, P. J.; Macedo, R. M. P. R.; Rocha, S. S.; Marques-Filho, S. Avaliação de risco como instrumento de gestão ambiental. Revista Produção On-line, v. 1, n. 1, p. 1-9, 2001. https://doi.org/10.14488/16761901.v1i1.595

Araujo, M. L. M. N.; Reinaldo, L. R. L. R.; Sousa, J. S.; Almeida, P. G.; Alves, L. S.; Wanderley, J. A. C. Impactos ambientais nas margens do Rio Piancó causados pela agropecuária. Revista Brasileira de Gestão Ambiental, v. 4, n. 1, p. 13-33, 2010.

Barbosa Filho, W. P.; Ferreira, W. R.; Azevedo, A. C. S.; Costa, A. L.; Pinheiro, R. B. Expansão da energia solar fotovoltaica no Brasil: impactos ambientais e políticas públicas. Revista de Gestão e Sustentabilidade Ambiental, v. 4, p. 628-642, 2015.

Brasil. Resolução CONAMA no 001, de 23 de janeiro de 1986. Disponível em: <http://www2.mma.gov.br/port/conama/re s/res86/res0186.html>. Acesso em: $12 \mathrm{dez}$. 2018.

Brown, A. E. P. Análise de risco. Boletim Técnico do GSI/NUTAU/USP, v. 3, n. 1, p. 1-7, 1998.

Campos, O. L. Estudo de caso sobre impactos ambientais de linhas de transmissão na Região Amazônica. BNDES Setorial, v. 32, p. 231-266, 2010.

Comunello, F.; Trindade, L. L.; Deimling, M. F. Modelo para avaliação ambiental em sistemas produtivos industriais: um estudo de caso em uma indústria de transformação de plástico. Revista de Gestão Ambiental e Sustentabilidade, v. 6, n. 1, p. 87-106, 2017.

Deus, R. M.; Bakonyi, S. M. C. O impacto da agricultura sobre o meio ambiente. Revista Brasileira de Gestão Ambiental, v. 6, n. 1, p. 21-28, 2012. https://doi.org/10.5902/ 223611705625

ELETROBRÁS - Centrais Elétricas Brasileiras S. A. The Brazilian Power Sector's Environmental Máster Plan - 1991/1993: Summary. Brasília: Eletrobrás, 1990.
Eletrobrás Eletronorte. Relatório R3 caracterização e análise socioambiental LT 500 kV Jauru/Cuiabá C2. Brasília: Gerência de Estudos e Projetos Ambientais de Transmissão - EEMT, 2014.

Furnas - Furnas Centrais Elétricas S. A. Linha de Transmissão de 759 kV Itaperebá Tijuco Preto II: Relatório dos Estudos de Avaliação de Impacto Ambiental. Promon Engenharia S. A., 1987.

Mazo, C. G. D.; Pampolini, C. P. G. Sustentabilidade nas organizações: a aplicação do Método Gaia de Gerenciamento de Impactos Ambientais em uma empresa. Revista de Gestão Ambiental e Sustentabilidade, v. 4, n. 3, p. 103-121, 2015.

NRC - National Research Council. Risk assessment in the federal government: Managing the process. Washington, DC: National Academy Press, 1983.

Oliveira, R. R.; Zaú, A.S. Impactos da instalação de linhas de transmissão sobre ecossistemas florestais. Floresta e Ambiente, v. 5, n. 1, p. 184-191, 1998.

Pereira, D. H.; Ferreira, L. F.; Souza, M. M.; Ferreira, D. D. M. Matriz de aspectos e impactos ambientais como ferramenta de evidenciação de contingências ambientais. Revista de Gestão Ambiental e Sustentabilidade, v. 3, n. 2, p. 74-91, 2014.

Sella, B. C. Comparativo entre as técnicas de análise de riscos APR e HAZOP. Curitiba: Universidade Tecnológica Federal do Paraná, 2014. (Monografia de Especialização).

Siqueira, J. E.; Henkes, J. A. Impactos gerados por represas de usinas hidrelétricas: o caso da Usina Hidrelétrica de Manso. Revista de Gestão e Sustentabilidade Ambiental, v. 3, n. 1, p. 359-372, 2014

WBM - Consultoria e Gestão Ambiental. Estudo de Impacto Ambiental e Relatório de Impacto Ambiental da Linha de Transmissão 500 kV SE Jauru - SE Cuiabá C2. Cuiabá: Santa Lucia Transmissora S. A. SEMA/MT, 2016. v. 2.

Informação da Licença: Este é um artigo Open Access distribuído sob os termos da Licença Creative Commons Attribution, que permite uso irrestrito, distribuição e reprodução em qualquer meio, desde que a obra original seja devidamente citada. 